\title{
Pemanfaatan Panas Sisa Pembakaran Bata Merah di Daerah Setiti Kab. Muaro Jambi
}

\author{
Myson $^{1}$, Venny Yusiana ${ }^{2}$ \\ Dosen Teknik Listrik Universitas Batanghari \\ Correspondence email: myson_ade1@yahoo.com
}

\begin{abstract}
Abstrak. Pada proses pembakaran bata merah di desa Setiti Kecamatan Jaluko Kabupaten Muaro Jambi terdapat suhu yang akan dilepaskan ke lingkungan yang cukup tinggi yaitu $300{ }^{\circ} \mathrm{C}$. Panas yang tinggi ini dapat dimanfaatkan untuk proses pengeringan bata merah mentah yang masih basah dengan dibuatkan saluran pengering dengan menekan udara dingin menuju tungku pembakaran sebanyak 2,586 kg/dt dengan asumsi efisiensi $80 \%$ dan kecepatan aliran udara dingin $2 \mathrm{~m} / \mathrm{dt}$ yang mana udara panas yang akan dilepas ke lingkungan nantinya adalah sebesar $70{ }^{\circ} \mathrm{C}$. Proses ini dapat terjadi dengan menahan temperatur tersebut selama 10,16 jam.
\end{abstract}

Kata kunci: Efisiensi, Tungku, Pembakaran, Bata merah

\section{PENDAHULUAN}

Membangun rumah menggunakan bata merah merah merupakan sesuatu yang biasa dan lumrah ditengah-tengah masyarakat kita. Pesatnya pembangunan di sektor perumahan dan properti menjadikan kebutuhan terhadap bata merah semakin meningkat.

Pada proses pembuatan bata merah setelah bata merah dicetak proses selanjutnya adalah di jemur. Proses penjemuran ini membutuhkan waktu yang cukup lama yaitu 2 hingga 3 minggu, tergantung cuaca. Jika hujan maka waktu proses pengeringan menjadi lebih lama, tapi jika hari panas bisa 2 minggu. Setelah kering barulah bata merah tersebut dibakar dengan perlahan-lahan hingga suhu mencapai $1100{ }^{\circ} \mathrm{C}$.

Dari hasil penelitian sebelumnya yang dilakukan di ketahui bahwa daerah sekitar tungku memiliki temperatur yang sangat panas dan dari data pengukuran diketahui bahwa temperatur setelah semua bahan bakar terbakar berada diatas $300{ }^{\circ} \mathrm{C}$ selama lebih kurang 2 hari 1 malam. Sementara pada saat awal proses pembakaran temperatur sekitar tungku berada pada suhu 70 hingga $85{ }^{\circ} \mathrm{C}$ selama 1 hari satu malam. Sehingga hal ini merupakan suatu peluang untuk mengurangi waktu proses pengeringan bata merah.

Dengan memanfaatkan panas sisa ini dengan maka waktu pengeringan akan dapat di persingkat, sehingga jumlah produksi bata merah dalam satu tahun dapat meningkat. Dengan mengasumsikan terjadi penyingkatan waktu proses pengeringan sebanyak 50\% maka jumlah produksi dapat meningkat hingga $200 \%$.

\section{Perumusan Masalah}

Produksi bata merah secara tradisional membutuhkan waktu yang lama. Waktu yang lama ini banyak disebabkan oleh proses pengeringan yang hanya mengandalkan panas matahari. Berdasarkan data yang didapat dilapangan untuk satu kali proses produksi bata merah sebanyak 30.000 butir dibutuhkan waktu hingga 1 bulan kerja. Selama ini panas sisa pembakaran terbuang secara sia-sia kelingkungan dengan temperatur yang cukup tinggi yaitu $300{ }^{\circ} \mathrm{C}$. Hal ini berdampak kepada lingkungan sekitar dan berkontribusi pada meningkatnya temperatur bumi. Proses pembakaran dilakukan selama 5 hingga 7 hari tanpa henti (non stop).

Adapun tujuan dari pemanfaatan panas sisa pembakaran bata merah adalah untuk memperpendek waktu pengeringan dalam proses produksi bata merah di daerah Setiti Kab Muaro Jambi, sehingga produksi bata merah dapat ditingkatkan produksinya.

Dengan pendeknya waktu produksi maka untuk satu kali pembakaran yang menghasilkan 30.000 butir bata merah dibutuhkan waktu lebih singkat dari pada tidak memanfaatkan panas sisa pembakaran, yaitu kurang dari satu bulan.

Adapun manfaat penelitian ini adalah: 1) Produksi bata merah tradisional di daerah setiti kab Muaro jambi dapat ditingkatkan; 2) Dengan meningkatnya produksi bata merah maka efisiensi proses pembuatan bata merah di daerah setiti kab Muaro Jambi juga meningkat sehingga biaya produksi akan menurun; 3) Dengan memanfaatkan panas sisa pembakaran maka akan terjadi pengurangan penggunaan bahan bakar kayu dalam proses produksi bata merah

\section{Pembakaran Bata Merah}

Bata merah adalah bahan bangunan yang telah lama dikenal dan banyak digunakan oleh masyarakat seiring dengan meningkatnya jumlah dan laju pertambahan penduduk. Penggunaan bata merah banyak digunakan untuk aplikasi perumahan. Oleh karena itu, kebutuhan terhadap bata merah merah dapat terpenuhi dengan menyediakan bata 
merah merah yang memenuhi persyaratan teknis, mudah didapat dan harga yang murah sehingga dapat dijangkau oleh masyarakat.

Pada umumnya pembuatan bata merah merah dengan cara dibakar pada suhu $800{ }^{\circ} \mathrm{C}$ hingga $1100^{\circ} \mathrm{C}$ sehingga tidak dapat hancur bila direndam air, sedangkan pembakarannya dapat menggunakan sekam padi atau menggunakan kayu bakar atau batu bara sehingga proses ini akan menimbulkan polusi udara melalui emisi $\mathrm{CO}_{2}$ dan gas lainnya yang ditimbulkannya serta mempersulit dan memperlama proses pembuatan bata merah. Disamping itu, pembuatan bata merah merah dipengaruhi oleh kondisi cuaca, karena proses pengeringan bata merah merah yang sudah dicetak banyak mengandalkan panas cahaya matahari, dan ketika terjadi musim hujan akan mengganggu proses pembuatannya sehingga produktifitas bata merah akan berkurang dan lebih lama. Sedangkan bahan dasar bata merah biasanya diambil dari galian tanah sawah yang subur atau tanah liat, hal ini dapat merusak lingkungan yang disebabkan karena pertambangan tanah liat secara berlebihan.

Pembakaran yang dilakukan tidak hanya memperhatikan suhu yang di inginkan, melainkan juga memperhatikan kecepatan pembakaran. Selama proses pembakaran terjadi perubahan fisika dan kimia serta mineralogy dari tanah liat tersebut. Proses pembakaran batu merah harus berjalan seimbang dengan kenaikan suhu.

1. Tahap pertama adalah penguapan (pengeringan), yaitu pengeluaran air pembentuk bata merah merah yang terjadi pada temperatur kira-kira $120^{\circ} \mathrm{C}$.

2. Tahap oksidasi, terjadi pembakaran sisa-sisa tumbuhan (karbon) yang terdapat didalam tanah liat. Proses ini berlangsung pada temperatur $650^{\circ} \mathrm{C}-800^{\circ} \mathrm{C}$.

3. Tahap pembakaran penuh. Bata merah merah dibakar hingga matang dan terjadi proses sintering hingga menjadi bata padat. Temperatur matang bervariasi antara $920{ }^{\circ} \mathrm{C}-1020^{\circ} \mathrm{C}$ tergantung pada sifat tanah liat yang dipakai.

4. Tahap penahanan. Pada tahap ini terjadi penahanan temperatur selama 1-2 jam.

Pada tahap pertama hingga tahap ke empat kenaikan temperatur dilakukan secara perlahan agar tidak terjadi keretakan yang akan menyebabkan kerugian pada produksi bata merah. Kerugian yang terjadi antara lain pecah, noda hitam, penyusutan yang berlebihan dan lain-lain.

Temperatur dalam tungku dinaikan dengan cara menambah kayu bakar yang dimulai dari temperatur kamar sampai $120{ }^{\circ} \mathrm{C}$ (untuk menghilangkan sisa air yang ada) kemudian, dilanjutkan dengan $800{ }^{\circ} \mathrm{C}$ (dipertahankan dengan waktu tertentu) dengan tujuan menghilangkan karbon pada abu serta menghilang kan molekul-molokul air dalam tungku. Kemudian dinaikan kembali temperatur yang ada hingga temperatu $950-1000{ }^{\circ} \mathrm{C}$

Tidak jarang temperatur dinaikan kembali hingga $1020{ }^{\circ} \mathrm{C}$ untuk mendapatkan standar SNI sehingga bata merah yang telah dibakar pada temperatur $1000-1020^{\circ} \mathrm{C}$. Hal ini terjadi karena semakin tinggi temperatunya maka tanah akan mendekati sifat keramik dimana partikel-partikelnya hampir mengalami ikatan yang sempurna. Partikelpartikel mengalami perubahan bentuk yang saling mengisi pori-pori sehingga bata merah akan kuat dan keras. Setelah proses pembakaran berlangsung selanjutnya proses pendinginan yang membutuhkan waktu 2 hingga 4 hari dan pada hari selanjutnya barulah bata merah dapat di bongkar untuk dijual.

\section{Kalor Pembakaran}

Kalor merupakan panas yang bisa berpindah dari benda yang memiliki kelebihan kalor menuju benda yang kekurangan kalor. Kalor biasanya dinyatakan dalam suhu. Dalam satuan internasional, kalor dinyatakan dengan Joule. Satuan lainnya dinyatakan dengan kalori.

1 kalori didefinisikan sebagai banyaknya kalor yang diperlukan untuk menaikan temperatur air sebanyak $1 \mathrm{~kg}$ air sebesar $1^{\circ} \mathrm{C}$.

1 kalori $=4.2$ joule dan 1 joule $=0.24$ kalori

\section{Kalor Jenis}

Kalor jenis adalah banyaknya kalor yang diserap atau diperlukan oleh 1 gram zat untuk menaikkan suhu sebesar

$1^{\circ} \mathrm{C}$. Kalor jenis juga diartikan sebagai kemampuan suatu benda untuk melepas atau menerima kalor. Masing-masing benda mempunyai kalor jenis yang berbeda-beda. Satuan kalor jenis ialah $\mathrm{J} / \mathrm{kg}^{\circ} \mathrm{C}$.

\section{Kapasitas Kalor}

Kapasitas kalor adalah jumlah kalor yang diserap oleh benda bermassa tertentu untuk menaikkan suhu sebesar

$1^{\circ} \mathrm{C}$. Satuan kapasitas kalor dalam sistem international ialah $\mathrm{J} / \mathrm{K}$.

$\mathbf{h}=\mathbf{m} . \mathbf{c} \cdot \Delta \mathbf{T}$

Keterangan:

- h : banyaknya kalor yang diterima atau dilepas oleh suatu benda ( $\mathrm{J})$

- $\mathrm{m}$ : massa benda yang menerima atau melepas kalor $(\mathrm{kg})$

- c : kalor jenis zat $\left(\mathrm{J} / \mathrm{kg}^{\circ} \mathrm{C}\right)$

- $\Delta \mathrm{T}$ : perubahan suhu $\left({ }^{\circ} \mathrm{C}\right)$ 


\section{Rumus Kalor Jenis}

\section{$\mathbf{c}=\mathbf{h} / \mathbf{m} . \Delta \mathbf{T}$}

Keterangan:

- $\mathrm{c}=$ kalor jenis zat $\left(\mathrm{J} / \mathrm{kg}^{0} \mathrm{C}\right)$

- $\mathrm{h}=$ banyaknya kalor yang dilepas atau diterima oleh suatu benda (Joule)

- $\mathrm{m}=$ massa benda yang menerima atau melepas kalor $(\mathrm{kg})$

- $\Delta \mathrm{T}=$ perubahan suhu $\left({ }^{\circ} \mathrm{C}\right)$

Rumus Kapasitas Kalor

\section{$\mathbf{C}=\mathbf{h} / \Delta \mathbf{T}$}

Keterangan:

- $\mathrm{C}=$ kapasitas kalor $(\mathrm{J} / \mathrm{K})$

- $\mathrm{h}=$ banyaknya kalor $(\mathrm{J})$

- $\Delta \mathrm{T}=$ perubahan suhu $(\mathrm{K})$

Selain itu, ada rumus lain untuk menentukan kapasitas kalor itu sendiri, yaitu: $\mathrm{C}=\mathrm{m}$. $\mathrm{c}$

Keterangan:

- $\mathrm{C}=$ kapasitas kalor $(\mathrm{J} / \mathrm{K})$

- $\mathrm{m}=$ massa benda yang menerima atau melepas kalor $(\mathrm{kg})$

- $\mathrm{c}=$ kalor jenis zat $(\mathrm{J} / \mathrm{kg} . \mathrm{K})$

Menurut Joseph Black (1729 - 1799) menyatakan bahwa kalor yang diterima oleh suatu benda sama dengan kalor yang dilepas oleh benda tersebut.

Secara lebih rinci rumus asas black pada suhu campuran sebagai berikut:

$\mathrm{Q}_{\text {suhu yang tinggi }}=\mathrm{Q}_{\text {suhu yang rendah }}$ (hasil campuran)

Dengan menggunakan persamaan tersebut akan didapatkan suhu campuran dari dua atau lebih zat yang berbeda. $\mathrm{m}_{1} \mathrm{Cp}_{1}\left(\mathrm{~T}_{1}-\mathrm{T}_{\mathrm{c}}\right)=\mathrm{m}_{2} \mathrm{Cp}_{2}\left(\mathrm{~T}_{\mathrm{c}}-\mathrm{T}_{2}\right)$

\section{Tungku Pembakaran Tradisional}

Proses pembakaran merupakan langkah yang sangat penting dalam memproduksi bata merah. Dalam proses pembakaran dibutuhkan tungku pembakaran yang sesuai dengan jumlah bata merah mentah yang akan dibakar. Untuk mendapatkan hasil yang maksimal perlu diperhatikan distribusi panas pada tungku agar merata. Hal ini akan berdampak pada kualitas bata merah dan mengurangi jumlah bata merah yang gagal dalam proses pembakaran. Semakin tidak merata panas pembakaran semakin besar pula tingkat kegagalan produksi bata merah tersebut.
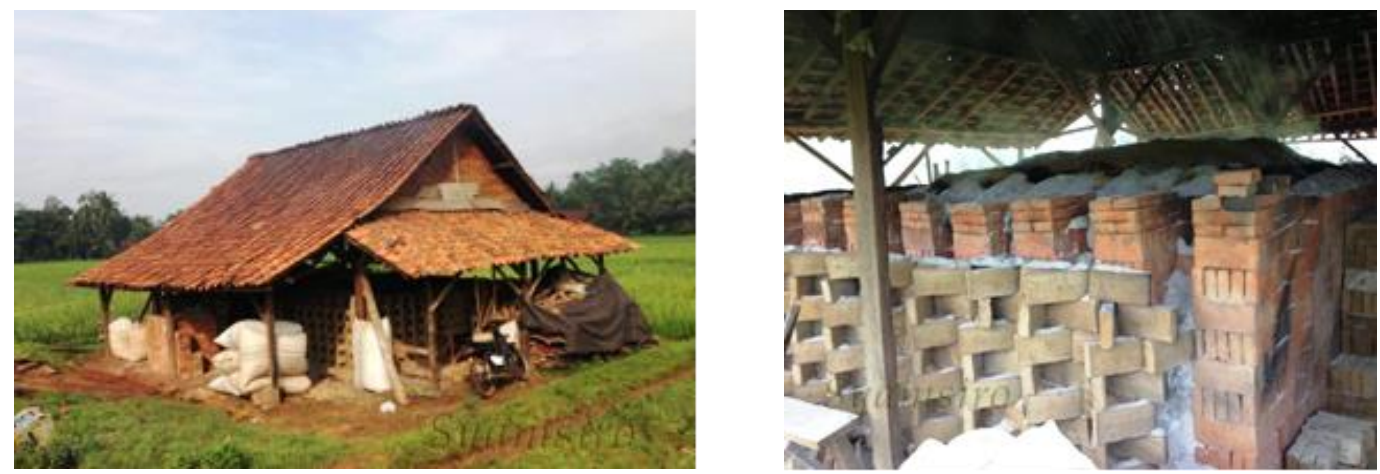

Gambar 1. Tungku pembakaran bata merah Tradisional

\section{METODE}

Penelitian ini menggunakan metode eksperimen dan literatur. Pada penelitian ini akan dibuat perencanaan terhadap sistim tungku pembakaran bata merah. Data yang didapat pada penelitian terdahulu akan digunakan sebagai data primer temperatur yang akan direncanakan untuk dimanfaatkan sebagai sumber panas untuk proses pengaringan. Hal ini akan berfungsi sebagai pengganti sinar matahari guna proses pengeringan dan diharapkan dengan proses ini akan meningkatkan kecepatan proses pengeringan tersebut.

Pada penelitian ini akan diambil data mengenai kandungan air (water content) pada bata merah yang baru dicetak. Kemudian dengan mambandingkan berat bata merah basah dengan bata merah yang kering siap dibakar akan didapatkan akan didapatkan kandungan air yang harus dihilangkan dalam bentuk persen.

Banyaknya kandungan air (water content) yang akan dihilangkan dihitung dengan proses termodinamika. Adapun proses termodinamika yang berlaku adalah dengan cara konveksi, konduksi dan terakhir konveksi. Namun 
karena konduksi yang terjadi sangat kecil yang diakibatkan meratanya kandungan air pada bata merah mentah menyebabkan kebutuhan kalornya dapat diabakan. Sehingga cara konveksi yang sangat berperan dalam proses pengeringan bata merah mentah tersebut.

$\mathbf{Q}=\mathbf{m} . \mathbf{c} \cdot \Delta \mathbf{T}$

\section{HASIL DAN PEMBAHASAN}

Pada penelitian terdahulu didapatkan data bahwa panas yang keluar dari tungku pembakaran bata merah berada pada kisaran $300{ }^{\circ} \mathrm{C}$. Temperatur tersebut berada pada tungku pembakaran selama lebih kurang 2 hari atau 48 jam dan seterusnya temperatur ini perlahan akan menurun hingga temperatur $70{ }^{\circ} \mathrm{C}$. Penurunan temperatur tersebut membutuhkan waktu hingga 2 hari atau 48 jam. Keesokan hari barulah proses pembakaran bata merah ini dapat di bongkar untuk dijual ke konsumen.
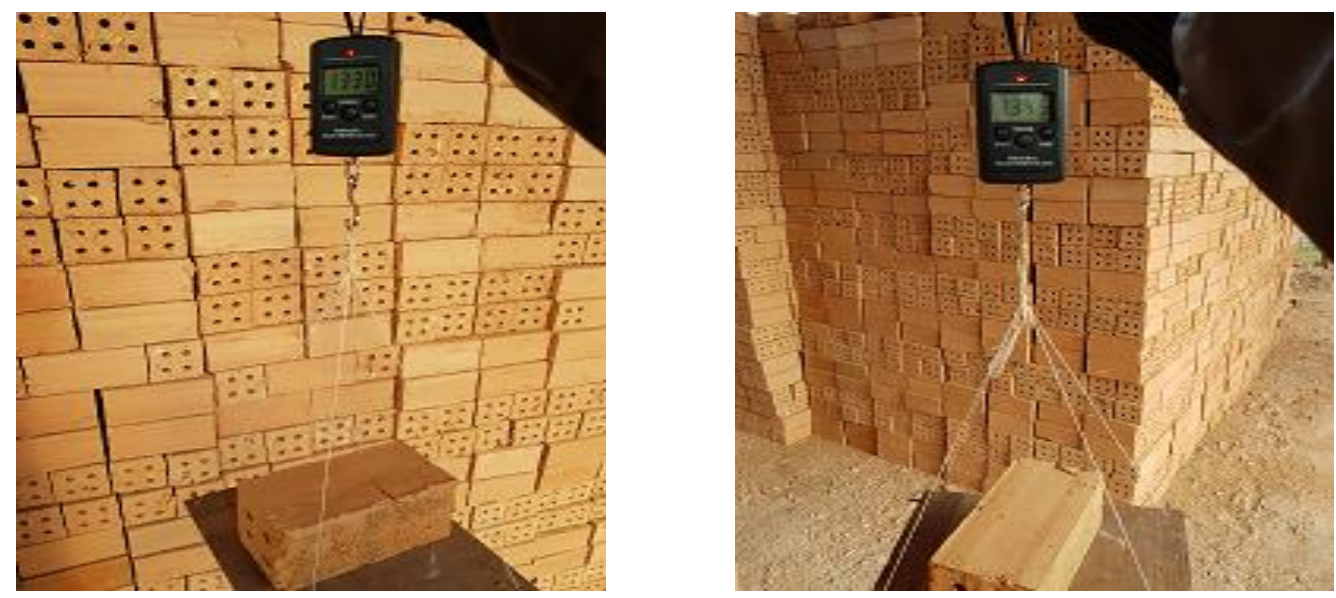

Gambar 2. Penimbangan benda uji

Kemudian dimensi dari bata merah yang diproduksi masyarakat desa Setiti Kecamatan Jaluko Kab Muaro Jambi tersebut dalam keadaan basah atau baru dicetak adalah 7,5 $\mathrm{cm}$ x 7,5 cm x $17 \mathrm{~cm}$. Adapun berat basah dari beberapa sampel yang diambil dapat dilihat pada tabel berikut.

Tabel 1. Data berat bata merah

\begin{tabular}{cccc}
\hline No & Berat Basah $(\mathbf{g})$ & Berat $\mathbf{1} \mathbf{2}$ Kering $(\mathbf{g})$ & Berat Kering $(\mathbf{g})$ \\
\hline 1 & 1860 & 1600 & 1320 \\
2 & 1885 & 1610 & 1322 \\
3 & 1885 & 1612 & 1295 \\
4 & 1885 & 1615 & 1275 \\
5 & 1885 & 1590 & 1330 \\
6 & 1920 & 1595 & 1345 \\
7 & 1920 & 1590 & 1260 \\
8 & 1920 & 1595 & 1260 \\
9 & 1940 & 1610 & 1310 \\
10 & 1910 & 1605 & 1315 \\
11 & 1925 & 1610 & 1295 \\
12 & 1925 & 1605 & 1296 \\
13 & 1905 & 1600 & 1310 \\
14 & 1835 & 1590 & 1315 \\
15 & 1870 & 1595 & 1280 \\
16 & 1870 & 1590 & 1325 \\
17 & 1855 & 1600 & 1315 \\
18 & 1900 & 1600 & 1312 \\
19 & 1900 & 1605 & 1320 \\
20 & 1850 & 1610 & 1280 \\
\hline
\end{tabular}

Sumber: Data penelitian (2019)

Dari tabel diatas didapatkan berat basah rata-rata bata merah yang dibuat didesa setiti kecamatan jambi luar kota kabupaten muaro jambi adalah 1892,25 gram dan berat rata-rata kering siap bakar adalah 1304 gram, sehingga didapatkan persentase kandungan air (water content) pada bata merah tersebut adalah $45 \%$ atau dalam satuan berat yaitu 588,25 gram. 
Pada proses pengeringan ini akan memanfaatkan panas yang dihasilkan dari tungku pembakaran yang memiliki temperatur hingga $300{ }^{\circ} \mathrm{C}$ secara paksa. Tungku yang panas tersebut akan di tiup dengan menggunakan udara sekitar sehingga panas yang dimiliki tungku akan bergerak menuju ujung dari lorong yang berfungsi sebagai oven dengan kecepatan aliran udara yang tertentu. Dengan pertemuan udara segar yang bertemperatur $25{ }^{\circ} \mathrm{C}$ dengan tungku yang bertemperatur $300{ }^{\circ} \mathrm{C}$ akan menghasilkan suhu campuran dengan prinsip kekekalan bahwa panas yang dilepas sama dengan panas yang diterima $\mathrm{Q}$ out $=\mathrm{Q}$ in.

Saluran panas ini akan mengalirkan udara dingin melalui mulut saluran dengan ukuran rencana lebar $2 \mathrm{~m}$ dan tinggi $1 \mathrm{~m}$, sehingga luas saluran adalah $2 \mathrm{~m}^{2}$. Udara dingin akan dialirkan secara paksa dengan menggunakan blower ataupun kipas angin dengan kecepatan rencana $1 \mathrm{~m} / \mathrm{dt}$. Kecepatan aliran udara ini direncanakan perlahan agar terjadi kontak yang lebih lama antara panas yang ada pada tungku pembakaran dengan udara dingin yang masuk, sehingga azas black dapat terjadi dengan maksimal.

Dengan kecepatan dan luas laluan maka volume aliran adalah sebesar $2 \mathrm{~m}^{3} / \mathrm{dt}$ dengan demikian masa aliran adalah $2,586 \mathrm{~kg} / \mathrm{dt}$ dengan masa jenis udara adalah $1,293 \mathrm{~kg} / \mathrm{m}^{3}$.

Karena masa udara yang masuk akan mengalami kehilangan akibat kebocoran sistim dengan asumsi efisiensi $80 \%$, maka masa udara yang keluar adalah:

$$
\begin{aligned}
\mathrm{m}_{\text {out }} & =\mathrm{m}_{\text {in }} \times 80 \% \\
& =2,586 \mathrm{~kg} / \mathrm{dt} \times 80 \% \\
& =2,0688 \mathrm{~kg} / \mathrm{dt}
\end{aligned}
$$

Dengan menggunakan azas black maka:

$\mathrm{m}_{\text {in }} \mathrm{Cp}(\mathrm{T} 1-\mathrm{Tc})=\mathrm{m}_{\text {out }} \mathrm{Cp}(\mathrm{Tc}-\mathrm{T} 2)$

$2,586 \times 12 \mathrm{~J} / \mathrm{dt} \cdot \mathrm{m} .{ }^{0} \mathrm{C} \times\left(300{ }^{\circ} \mathrm{C}-\mathrm{Tc}\right)=2 \mathrm{~kg} / \mathrm{dt} \times 12 \mathrm{~J} / \mathrm{dt} \cdot \mathrm{m} .{ }^{\circ} \mathrm{C} \times\left(\mathrm{Tc}-25^{\circ} \mathrm{C}\right)$

$\mathrm{Tc}=180{ }^{\circ} \mathrm{C}$

Kebutuhan Entalphi (h) untuk menjadikan uap air pada temperatur $100{ }^{\circ} \mathrm{C}$ dan tekanan 1,013 bar atau 1 atm adalah $2676 \mathrm{KJ} / \mathrm{kg}$. Karena air yang terkandung pada bata merah mentah adalah 0,588 kg dengan demikian entalphi (h) yang dibutuhkan adalah 1573,488 KJ.

Pada umumnya produsen yang ada di desa setiti kecamatan jaluko kabupaten muaro jambi menyusun bata merah untuk dikeringkan adalah dengan susunan melintang sehingga jika dihubungkan dengan proses pengeringan ini area yang akan terkena langsung dengan udara panas adalah 7,5 $\mathrm{cm} \mathrm{x} 17 \mathrm{~cm}$ sehingga areanya adalah :

$$
\begin{aligned}
A_{\text {bata merah }} & =0,075 \times 0,17 \\
& =0,01275 \mathrm{~m}^{2}
\end{aligned}
$$

Berdasarkan data penelitian yang ada nilai panas jenis tanah liat (bahan baku bata merah) adalah $\mathrm{k}=2,3$ $\mathrm{W} / \mathrm{m}^{0} \mathrm{C}$ (Puji Kumala Dewi)

Dan temperatur rencana saat keluar dari lorong pengering (T2) adalah $=70{ }^{\circ} \mathrm{C}$. Sementara kebutuhan entalphi untuk proses pengeringan tersebut $\mathrm{q}=1.573 .488 \mathrm{~J}$

Maka diperlukan waktu penahanan agar terjadi kontak antara udara panas dengan bata merah mentah (basah) adalah:

$\mathrm{q} \quad=\mathrm{kA}(\mathrm{dT} / \mathrm{dx})$

1.573.488 J $=2,3 \mathrm{~J} / \mathrm{dt} \cdot \mathrm{m} .{ }^{0} \mathrm{C} \times 0,01275 \mathrm{~m}^{2} \mathrm{x}(180-70)^{0} \mathrm{C} / 0,075 \mathrm{~m}$

$$
=36584 \mathrm{dt} \quad=10,16 \mathrm{jam}
$$

Maka penahanan temperatur agar terjadi pengeringan pada bata merah mentah yang basah tersebut dibutuhkan waktu untuk kontak selama 10,16 jam.

\section{SIMPULAN}

Pada penelitian ini dapat disimpulkan bahwa panas sisa yang terdapat pada proses pembakaran bata merah di desa Setiti Kecamatan Jaluko Kabupaten Muaro Jambi yang berada pada suhu $300{ }^{\circ} \mathrm{C}$ dapat dimanfaatkan untuk proses pengeringan bata merah mentah yang masih basah dengan dibuatkan saluran pengering dengan menekan udara dingin menuju tungku pembakaran sebanyak 2,586 kg/dt dengan asumsi efisiensi $80 \%$ dan kecepatan aliran udara dingin $2 \mathrm{~m} / \mathrm{dt}$ yang mana udara panas yang akan dilepas ke lingkungan nantinya adalah sebesar $70{ }^{\circ} \mathrm{C}$. Proses ini dapat terjadi dengan menahan temperatur tersebut selama 10,16 jam. 


\section{DAFTAR PUSTAKA}

Van Vlack, Lawrence. H. 2004. Elemen - Elemen Ilmu Dan Rekayasa Material. Jakarta: Erlangga Adrian Bejan, 1988, 'Advanced Engineering Thermodynamics', Jhon Wiley\&son.Inc

Hasan Basri, Dr.Ir, 2007, ' Teknik Kogenerasi (bahan kuliah),PPs Unsri, Palembang.

Roger Kinsky M.Eng,Sc.,B.E.,B.Sc, 'Applied Heat',An Introduction to thermodynamics, Second edition.

Suasmoro, Dr. 2000. Fisika Keramik. Surabaya. Jurusan Fisika FMIPA ITS.

Aji, Setyo.B dan Anjar. 2009. The Role Of a Coal Gasification Fly Ash as Clay Addive in Building Ceramic. Journal of the European Ceramic Sosiety 26 (2006) 3783-3787.

Nelly, Komang Sundari 2010. Pengaruh Perlakuan Suhu Bakar Pada Massa Bodi Keramik Stone Kode BL 1 Terhadap Parameter Penyusutan dan Peresapan Air. Bali: Skripsi.

P.U. 1991. SNI 15 -2094 -1991 tentang Bata Merah Pejal. Jakarta: Pekerjaan Umum.

Subiyanto, Hari Subowo. 2003. Pengaruh Temperatur Sintering terhadap Sifat Mekanik Keramik Insulator Listrik. Surabaya: ITS.

Surdia, Tata dan Kenji Chijiwa. Pengetahuan Bahan Teknik. Jakarta: Pradya Paramita, 2006.

Prayitno, Dody. Teknologi Rekayasa Material. Jakarta: 2010

Rahmat Muhammad Rais, "Perancangan Dan Pembuatan Tungku Heat Treatment" Jurnal Imiah Teknik Mesin, Vol. 3, No.2 Agustus 2015 Universitas Islam 45 Bekasi, http://ejournal.unismabekasi.ac.id/

Chapman \& Hall. Ltd, 1961,"Waste Heat Recovary, Twenty one chapters base on a conferency held by the Institute of Fuel', Institute of Fuel, London

Moran, J Michael \& Shapiri N Howard,1999,"Fundamental Engineering Thermodynamics", fourth edition, Jhon Wiley

Reynold, C William \& Perkins C Henry, 1977,'Termodinamika Teknik”, Alih Bahasa Filino Harahap, 1982, Erlangga

Puji Kumala Pertiwi, Deril Ristiana,'Uji Konduktivitas Termal pada Interaksi Dua Logam Besi ( $F e$ ) dengan 3 Variasi Bahan Berbentuk Silinder", Jurusan Fisika, Fakultas MIPA, Institut Teknologi Sepuluh Nopember (ITS) 